\title{
Reduced Antinociceptive Effect of Repeated Treatment with a Cannabinoid Receptor Type 2 Agonist in Cannabinoid-Tolerant Rats Following Spinal Nerve Transection
}

\author{
Matthew S. Alkaitis ${ }^{1,2}$, Christian Ndong1,3, Russell P. Landry III'1,3, \\ Joyce A. DeLeo ${ }^{1,3,4}$ and E. Alfonso Romero-Sandoval1,3,4 \\ ${ }^{1}$ Neuroscience Center at Dartmouth, Dartmouth Medical School, \\ ${ }^{2}$ Nuffield Department of Clinical Laboratory Sciences, John Radcliffe Hospital, \\ ${ }^{3}$ Department of Anesthesiology, Dartmouth-Hitchcock Medical Center, \\ ${ }^{4}$ Department of Pharmacology and Toxicology, Dartmouth-Hitchcock Medical Center, \\ $1,3,4$ USA \\ ${ }^{2} U K$
}

\section{Introduction}

In both preclinical and clinical studies, agents that activate cannabinoid receptors type 1 (CB1) and 2 (CB2) have shown promise in the treatment of pain (Wade et al., 2004; RomeroSandoval and Eisenach, 2007). Cannabinoids are licensed for the clinical treatment of cancer chemotherapy-associated nausea and vomiting (USA and Canada), immunodeficiency syndrome-associated loss of appetite and weight loss (USA and Canada), multiple sclerosisassociated spasticity (United Kingdom and Canada) and neuropathic pain (Canada). However, clinical use of cannabinoid compounds is limited both by undesirable neurological side effects and by induction of tolerance. In animal models, neurological side effects have been shown to be dependent on CB1 receptor but not CB2 receptor activation (Romero-Sandoval and Eisenach, 2007). Furthermore, sustained spinal or subcutaneous administration of the CB1 receptor agonist, WIN 55,212-2 has been shown to induce hypersensitivity and antinociceptive tolerance in naive mice and rats. In contrast, we (Romero-Sandoval and Eisenach, 2007; Romero-Sandoval et al., 2008a) and others (Yao et al., 2009) have shown that spinal CB2 receptor agonists (such as JWH015) relieve postoperative and neuropathic pain in rodent models without inducing neurological side effects or antinociceptive tolerance. Despite advancements in the molecular mechanisms involved in cannabinoid tolerance (Martini et al., 2010), a better understanding of the respective roles of CB1 and CB2 receptors is required to design effective therapies that do not induce tolerance. Further advances in this area may also guide clinical treatment of patients who have already developed tolerance through prior exposure to non-selective cannabinoid agonists for recreational or medical purposes. 
Using the L5 nerve transection (L5NT) rodent model of chronic neuropathic pain, this study was designed to test: 1) whether a non-selective cannabinoid agonist (CP55940) induces tolerance following repeated intrathecal (i.t.) administration in a model of neuropathic pain; 2) whether this antinociceptive tolerance could be reversed by the cessation of drug exposure; and 3) whether sustained spinal administration of the nonselective cannabinoid CP55940 affects antinociception induced by a CB2 receptor agonist (JWH015). To determine the site of action of these agonists we additionally examined expression levels and cellular localization of CB1 and CB2 receptors in the spinal cord of rats receiving either L5NT or sham surgery.

\section{Materials and methods}

\subsection{Animals and surgical procedures}

These studies were performed in accordance with the Guidelines for Animal Experimentation of the International Association for the Study of Pain (IASP) and after approval by the Institutional Animal Care and Use Committee at Dartmouth College (Dartmouth Medical School, Hanover, New Hampshire). Male Sprague-Dawley rats weighing 200-250 g (Harlan, Indianapolis, IN) at the start of surgery underwent L5NT surgery as previous described (Tanga et al., 2005). Briefly, rats were anesthetized with $2 \%$ isoflurane in oxygen and a small incision to the skin overlying L5-S1 was made followed by retraction of the paravertebral musculature from the vertebral transverse processes. The L6 transverse process was then partially removed to expose the L4 and L5 spinal nerves. The L5 spinal nerve was identified, lifted slightly, and transected. The wound was irrigated with saline and sutured in two layers. Sham surgeries were performed in other group of rats following the same procedure but without manipulating or injuring the nerves. The surgeries and anesthesia exposure lasted 15 - 20 minutes. Animals were housed individually and maintained in a 12:12 hr light/dark cycle with ad libitum access to food and water. Efforts were made to limit animal distress and to use the minimum number of animals necessary to achieve statistical significance.

\subsection{Tissue preparation, immunohistochemistry, imaging and image analysis}

After being anesthetized with $2-4 \%$ isoflurane in oxygen, rats were perfused transcardially with phosphate buffered saline $(0.01 \mathrm{M}, 150 \mathrm{ml})$ followed by $4 \%$ formaldehyde $(350 \mathrm{ml})$ at room temperature. The L5 spinal cord section was collected and placed in 30\% sucrose for $48-72 \mathrm{hr}$ at $4{ }^{\circ} \mathrm{C}$. The tissue was then frozen in O.C.T. Compound (Sakura Finetek, Torrance, CA) and stored at $-80{ }^{\circ} \mathrm{C}$. To determine the expression of spinal CB2 receptor immunohistochemistry was performed on transverse 20- $\mu \mathrm{m}$ L5 spinal cord free-floating sections by using the Vector ELITE ABC (Vector Labs, Burlingame, CA), avidin-biotin complex technique and a goat polyclonal antibody against the C-terminus of CB2 receptor (1:150, Santa Cruz biotechnology, Santa Cruz, CA, sc10076) as we have previously described (Romero-Sandoval et al., 2008a). Immunofluorescence was performed to determine the spinal CB1 receptor expression level using a rabbit polyclonal antibody (1:200, Cayman, Ann Arbor, MI) and a Alexa-Fluor ${ }^{\mathrm{TM}} 488$ Goat anti-Rabbit IgG1 secondary antibody (Molecular Probes, Eugene, Oregon). For CB1 receptor and CB2 receptor expression quantification, the sections were examined with an Olympus microscope, and images were captured with a Q-Fire cooled camera (Olympus, Melville, NY). We quantified the CB1 receptor or $\mathrm{CB} 2$ receptor expression, blinded to experimental conditions, as the number of 
pixels above a preset intensity threshold using SigmaScan Pro 5 as previously described (Romero-Sandoval and Eisenach, 2007; Romero-Sandoval et al., 2008b). For both CB1 receptor and $\mathrm{CB} 2$ receptor expression, the staining intensity was examined in a standardized area of superficial laminae (I-II) and deep laminae (III-V) of the L5 dorsal horn in 3-4 slices examined per animal.

Immunofluorescence was also used for dual labeling with specific cell markers and CB1 receptor or CB2 receptor. All sections were blocked in 5\% Normal Goat Serum (NGS) and $0.01 \%$ Triton-X-100 for 1 hour at $4{ }^{\circ} \mathrm{C}$. Sections were incubated in the appropriate primary antibody or antibodies diluted in a buffer composed of $1 \%$ NGS and 1\% Triton-X-100 in PBS overnight at $4{ }^{\circ} \mathrm{C}$. To determine the cellular localization of $\mathrm{CB} 1$ receptor or $\mathrm{CB} 2$ receptor we co-labeled antibodies for CB1 receptor and CB2 receptor with the following cellular markers (antibodies): rabbit polyclonal anti-Iba-1 for microglia (1:1000, Wako Pure Chemical Industries, Richmond, VA), mouse polyclonal anti-GFAP for astrocytes (1:400, Sigma, Saint Louis, Missouri), mouse polyclonal antibody anti- ED2/CD163 for perivascular cells (1:150, Serotec, Raleigh, NC), mouse polyclonal anti-Neuronal Nuclei, NeuN for neurons $(1: 10,000$, Chemicon, Billerica, Massachusetts).

The following secondary antibodies were used as indicated in table 1: Alexa-Fluor ${ }^{\mathrm{TM}} 488$ Goat anti-Rabbit IgG1 (Molecular Probes, Eugene, Oregon), Alexa-Fluor ${ }^{\mathrm{TM}} 488$ Goat antiMouse IgG1 (Molecular Probes, Eugene, Oregon), Alexa-Fluor ${ }^{\mathrm{TM}} 555$ Goat anti-Mouse IgG (Molecular Probes, Eugene, Oregon) and Alexa-Fluor ${ }^{\mathrm{TM}} 555$ Donkey anti-Goat IgG (Molecular Probes, Eugene, Oregon).

To avoid cross-reactivity between the secondary antibodies in the $\mathrm{CB}_{2}$ receptor colocalization experiments, sections were first incubated in Alexa-Fluor ${ }^{\mathrm{TM}} 555$ Donkey antiGoat IgG (Molecular Probes, Eugene, Oregon) as described above, washed 2 times in PBS and then incubated in the appropriate Alexa-Fluor ${ }^{\mathrm{TM}} 488$ secondary antibody as described above. This protocol modification prevented binding of the Alexa-Fluor ${ }^{\mathrm{TM}} 555$ Donkey anti-Goat IgG to the goat-derived Alexa-Fluor ${ }^{\mathrm{TM}} 488$. The specificity of each antibody was tested by omitting the primary antibody on 1-3 additional sections. To avoid crossreactivity when co-staining with primary antibodies against Iba- 1 and $\mathrm{CB}_{1}$ receptors that are both rabbit-derived, a TSA Signal Amplification Kit was used following the manufacturer instructions (PerkinElmer LifeSciences Inc, Boston, MA). On the first day, normal immunofluorescence protocol was followed except that sections were incubated only in anti-CB $\mathrm{CB}_{1}$ receptor antibody at a concentration of 1:10,000. On the second day sections were washed 2 times for 5 minutes in PBS then incubated in a biotinylated Goat a Rabbit secondary antibody for 1 hour at $4{ }^{\circ} \mathrm{C}$. Sections were then subjected to another wash, incubated in SA-HRP (1:100) for 1 hour at $4{ }^{\circ} \mathrm{C}$, washed again and incubated in the TSA fluorophore $(1: 250)$ for 10 minutes at $4{ }^{\circ} \mathrm{C}$. Sections were then washed again and incubated overnight in the Iba-1 primary antibody (1:1000). The next day sections were subjected to normal day 2 immunofluorescence protocol to visualize Iba- 1 (described above). One control was included with only the anti- $\mathrm{CB}_{1}$ receptor primary antibody $(1: 10,000)$ and the Alexa 555 Goat a Rabbit secondary antibody to control for any crossreactivity that might cause $C_{1}$ receptor expression to appear in red. A second control included only the anti- $\mathrm{CB}_{1}$ receptor primary antibody and the TSA kit in order to visualize the staining achieved in the absence of the co-stain. Finally, a third control included the TSA kit, Iba-1 primary and the Alexa 555 Goat a Rabbit secondary antibody but excluded the anti- $\mathrm{CB}_{1}$ receptor primary antibody. This third control provided 
visualization of the non-specific background staining produced by the kit alone. All controls confirmed the specificity of the co-stain.

\begin{tabular}{|l|l|l|l|}
\hline $\begin{array}{l}\text { Antigen } \\
\text { (Co-stain) }\end{array}$ & Primary & Secondary & $\begin{array}{l}\text { Fluorophore optimal } \\
\text { excitation (nm) }\end{array}$ \\
\hline CB1 & Rabbit & Goat a Rabbit & 488 \\
\hline Iba1 (CB1) & Rabbit (Rabbit) & $\begin{array}{l}\text { Goat a Rabbit } \\
\text { (TSA Signal Amplification Kit) }\end{array}$ & $488(555)$ \\
\hline GFAP (CB1) & Mouse (Rabbit) & $\begin{array}{l}\text { Goat a Mouse } \\
\text { (Goat a Rabbit) }\end{array}$ & $488(555)$ \\
\hline ED2 (CB1) & Mouse (Rabbit) & $\begin{array}{l}\text { Goat a Mouse } \\
\text { (Goat a Rabbit) }\end{array}$ & $488(555)$ \\
\hline Iba1 (CB2) & Rabbit (Goat) & $\begin{array}{l}\text { Goat a Rabbit } \\
\text { (Donkey a Goat) }\end{array}$ & $488(555)$ \\
\hline GFAP (CB2) & Rabbit (Goat) & $\begin{array}{l}\text { Goat a Rabbit } \\
\text { (Donkey a Goat) }\end{array}$ & $488(555)$ \\
\hline ED2 (CB2) & Mouse (Goat) & $\begin{array}{l}\text { Goat a Mouse } \\
\text { (Donkey a Goat) }\end{array}$ \\
\hline NeuN (CB2) & Mouse (Goat) & $\begin{array}{l}\text { Goat a Mouse } \\
\text { (Donkey a Goat) }\end{array}$ \\
\hline
\end{tabular}

Table 1. Details of antibody selections for all immunofluorescense experiments, CB1: Cannabinoid receptor type 1, CB2: Cannabinoid receptor type 2, ED2: Perivascular cell marker, GFAP: Glial Fibrillary Acidic Protein, Iba-1: Ionized Calcium-Binding Adapter Molecule 1, NeuN: Neuronal Nuclei.

Stained sections were examined with an Olympus fluorescence microscope, and images were captured with a Q-Fire cooled camera (Olympus, Melville, NY). Confocal microscopy was also performed using a Zeiss LSM 510 Meta confocal microscope (Carl Zeiss AG, Oberkochen, Germany; Englert Cell Analysis Laboratory, Dartmouth). Merged color images were processed using Adobe Photoshop 7.0 (Adobe Systems, San Jose, CA).

\subsection{Behavioral testing}

Mechanical allodynia was evaluated by measuring the $50 \%$ withdrawal threshold using an up-down statistical method (Chaplan et al., 1994) and calibrated von Frey filaments $(1-60$ g, Stoelting, Wood Dale, IL). At each time point, two measurements were made on the paw ipsilateral to surgery in 5-10 min intervals, and the average of these values was used for data analyses. As an internal control, withdrawal thresholds were also measured in the paw contralateral to surgery (uninjured side). The withdrawal threshold was determined for each animal before surgery, 4 days after surgery (immediately before any pharmacological treatment), and after drug administration (different time points for different paradigms, see below). The investigator was blinded to drug treatment in all behavioral tests.

\subsection{Drugs and treatments}

Drugs were administered by intrathecal (i.t.) injection by means of lumbar puncture under brief inhalational anesthesia (2-4\% isoflurane in oxygen) using a Hamilton syringe and a 28- 
gauge 5/8-inch hypodermic needle. The needle was inserted intrathecally, on the midline between the fourth and fifth lumbar vertebrae. The correct injection site was confirmed with the stimulation of nerves in the cauda equina when the lumbar needle penetrated the dura and produced a brief but obvious movement of the tail and/or the hind paws. The animals regained consciousness 2-3 min after the discontinuation of anesthesia. Drugs were diluted in dimethylsulfoxide and saline in a ratio of 1:1 and administered in a volume of $15 \mu \mathrm{l}$ as previously described (Romero-Sandoval et al., 2008a). The drugs used were: the dual (CB1 receptor and CB2 receptor) cannabinoid receptor agonist CP55940 (5-(1,1-Dimethylheptyl)-2[5-hydroxy-2-(3-hydroxypropyl) cyclohexyl]phenol; Sigma Chemical Co., St. Louis, MO); the CB2 receptor agonist JWH015 ((2-Methyl-1-propyl-1H-indol-3-yl)-1-naphthalenylmethanone), the CB1 receptor antagonist AM281 (1-(2,4-Dichlorophenyl)-5-(4-iodophenyl)-4-methyl- $N-4$ morpholinyl-1H-pyrazole-3-carboxamide) and the CB2 receptor antagonist AM630 (6-Iodo-2methyl-1-[2-(4-morpholinyl)ethyl]-1H-indol-3-yl](4-methoxyphenyl)methanone), purchased from Tocris, Ellisville, MI.

\subsection{Repeated CP55940 administration and monitoring of behavioral effects}

Beginning four days after surgery, CP55940 (100 $\mu \mathrm{g}$ /injection, $\mathrm{n}=18)$ or vehicle $(\mathrm{n}=17)$ was administered in single daily injections (8:00-9:00 AM) for five days. This dose and i.t. administration method were chosen based on our previous study using CP55940 in the same model of neuropathic pain (Romero-Sandoval and Eisenach, 2007), and on a previous study that demonstrated induction of antinociceptive tolerance with another non-selective cannabinoid agonist WIN 55,212-2 (Gardell et al., 2002) at a dose of $100 \mu \mathrm{g}$ twice daily. Drugs and vehicle were administered i.t. based on previous evidence that spinal cord mechanisms drive induction of cannabinoid tolerance (Gardell et al., 2002). Two hours after each injection, mechanical withdrawal thresholds in both ipsilateral and contralateral hindpaws were evaluated as described above.

\subsection{Evaluation of response to acute CP55940 dose escalation in tolerant and non-tolerant animals}

CP55940 was acutely administered i.t. in 30-min interval escalating doses: 0.4, 2, 10 and 50 $\mu \mathrm{g}$ in L5NT animals $24 \mathrm{hr}$ before and $24 \mathrm{hr}$ after the repeated (5 day) treatment with CP55940 ( $n=5)$ or vehicle $(n=6)$. As a control, vehicle was administered i.t. using the same dose escalation paradigm in animals that had previously received L5NT followed by repeated (5 days) treatment with CP55940 ( $n=8)$. The antinociceptive effect of escalating doses of CP55940 was evaluated 15 min after every injection. The effectiveness and potency of CP55940 were calculated using these dose responses and were compared in both repeated CP55940 and repeated vehicle treatment groups. To determine whether cannabinoidmediated tolerance was reversed following the discontinuation of sustained CP55940 administration, the antinociceptive response to escalating doses of CP55940 were also measured two weeks after the last day of repeated CP55940 treatment (washout period). In summary, responses to acute CP55940 dose escalation (or vehicle) was evaluated in the following cases: 1) prior to any additional treatment, 2) 24 hours after repeated (5-day) treatment with CP55940, 3) 24 hours after repeated (5-day) treatment with vehicle, and 4) 2 weeks (washout period) after repeated (5-day) treatment with CP55940. To confirm that CP55940 induced its effects via CB1 receptor and CB2 receptor as we have previously demonstrated (Romero-Sandoval and Eisenach, 2007; Romero-Sandoval et al., 2008a), we 
administered CP55940 at a dose of $50 \mu \mathrm{g}$ in combination with vehicle, the CB1 receptor antagonist AM281 at a dose of $50 \mu \mathrm{g}$ or the CB2 receptor antagonist AM630 at a dose of 50 $\mu \mathrm{g}$ in a separate group of rats. Mechanical withdrawal threshold was determined $2 \mathrm{hr}$ after treatments.

\subsection{Evaluation of response to acute JWH015 dose escalation in tolerant and non-tolerant animals}

JWH015, a CB2 receptor agonist, was acutely administered i.t. in 30-min interval escalating doses: $0.4,2,10$ and $50 \mu \mathrm{g}$ in L5NT animals that had previously received repeated (5 days) treatment with CP55940 $(n=8)$ or vehicle $(n=8)$. Vehicle was acutely administered i.t. using the same dose escalation paradigm in animals that had previously received L5NT followed by repeated (5 days) treatment with CP55940 (n=8). The antinociceptive effect of escalating doses of JWH015 was evaluated 15 min after every injection and its efficacy and potency were quantified. The first set of experiments was performed $24 \mathrm{hr}$ after the last day of repeated CP55940 administration to test whether the cannabinoid-mediated tolerance influenced the antinociceptive effects of a CB2 receptor agonist administered acutely. The second set of experiments was performed two weeks after the last day of repeated CP55940 treatment (washout period) to test whether the potency and/or efficacy of the CB2 receptor agonist, JWH015 improves following the discontinuation of sustained CP55940 treatment. In summary, responses to acute JWH015 dose escalation (or vehicle) were evaluated in the following cases: 1) 24 hours after repeated (5-day) treatment with CP55940 or vehicle and 2) 2 weeks (washout period) after repeated (5-day) treatment with CP55940 or vehicle.

To confirm that JWH015 induced its effects via CB2 receptors as we have previously demonstrated (Romero-Sandoval and Eisenach, 2007; Romero-Sandoval et al., 2008a), we administered JWH015 at a dose of $50 \mu \mathrm{g}$ in combination with the CB2 receptor antagonist AM630 at a dose of $50 \mu \mathrm{g}$ or vehicle in a separate group of animals. Mechanical withdrawal threshold was determined $2 \mathrm{hr}$ after treatments.

\subsection{Evaluation of response to repeated $\mathrm{JWH} 015$ administration in tolerant and non-tolerant animals}

Following the washout period (two weeks after repeated administration of CP55940 or vehicle), JWH015 (50 $\mu \mathrm{g} /$ injection, $\mathrm{n}=9$ ) or vehicle $(\mathrm{n}=8)$ was administered in single daily injections (8:00-9:00 AM) for four days. Behavioral testing were performed before and $2 \mathrm{hr}$ after each injection. Antinociceptive tolerance was evaluated by testing mechanical withdrawal thresholds in the paw ipsilateral or contralateral to surgery.

\subsection{Assessment of neurological side effects}

Based on our previous studies (Romero-Sandoval and Eisenach, 2007; Romero-Sandoval et al., 2008a) righting and placing-stepping tests were used to evaluate motor reflexes; the bar test was used to evaluate catalepsy; vocalization was used as a sign of irritability or discomfort to manipulation and exploratory activity was used as a measure of awareness. These parameters were evaluated before, 20 minutes and $2.5 \mathrm{hr}$ after each injection (following behavioral mechanical hypersensitivity testing). The placing-stepping reflex was tested by placing the rostral aspect of the hind paws on the edge of a table and was quantified as the seconds in which the animals put the paws up and forward into a position to walk. A cut-off of $60 \mathrm{~s}$ was used. The bar test consists of placing the forelimbs on a bar of 
$\sim 1 \mathrm{~cm}$ of diameter and $10 \mathrm{~cm}$ above and parallel to a table, leaving the hind paws resting on the table. A cataleptic animal will stay in that position longer than a normal animal. The time in which the animal puts its forelimb on the table was recorded, using a cut off time of $60 \mathrm{~s}$. The righting test consists of placing the animal supine and recording the ability to right itself. Righting was scored on a scale of 0-3, 0 indicating normal righting reflex (an immediate and coordinated twisting of the body to an upright position), 1 indicating mild impairment (ability to completely right, but slowly), 2 indicating moderate impairment (ability to right the forelimbs slowly followed by the hind limbs with more difficulty) and 3 indicating severe impairment (inability to right in $20 \mathrm{sec}$ ). Vocalization was rated on a scale of 0-3, 0 indicating absent vocalization, 1 indicating some vocalization when manipulated, 2 indicating consistent vocalization when manipulated and 3 indicating vocalization even light touch. Exploratory activity was rated on a scale of 0-3 with 0 indicating normal activity, 1 indicating only head movements without vertical and/or horizontal exploration, 2 indicating no spontaneous movements and 3 indicating splayed posture with no spontaneous movements. All behavioral measures were performed twice and the average used for analyses.

\subsection{Statistical analyses}

The effects of L5NT surgery and drug injections on bar test, placing-stepping test and withdrawal thresholds were examined using the repetitive measurements one-way analysis of variance. If significant effects were found, Tukey's multiple comparison or Dunnett's test was conducted. Differences between groups were examined using two-way analysis of variance. If differences were found, the Bonferroni post test was used. In the acute antinociceptive effect studies, acute i.t. JWH015 50\% of maximum efficacy (ED50) and its 95\% confidence limits were calculated and compared between repeated CP55940 and repeated vehicle groups using Student's $t$ test. ED50s were calculated using the baseline and after-surgery withdrawal thresholds as maximum and minimum effect values respectively. Vocalization, righting test and exploratory activity data following treatment were compared using the Friedman Repeated Measures Analysis of Variance on Rank test. If significant effects were found, non-parametric Wilcoxon signed ranks tests were conducted comparing each time point to the baseline value (before surgery). Between group differences were compared at each time period using the Kruskal-Wallis test. Significant effects were further evaluated using the Mann-Whitney U test comparing only the novel treatment to control or agonist group. The effects of CP55940 in acute antinociception vs. CP55940 in the presence of CB1 receptor or CB2 receptor antagonist was evaluated by one-way ANOVA followed by Dunnett's post-test. The effects of JWH015 in acute antinociception in the presence of the CB2 receptor antagonist was evaluated by unpaired Student's t-test. Data are presented as mean \pm SEM. In all cases a $P$ value less than 0.05 was considered significant. SigmaStat and GraphPad inStat software were used for statistical analyses.

\section{Results}

\subsection{Spinal cord CB1 and CB2 receptor expression and cellular localization}

Compared to rats receiving sham surgery, rats receiving L5NT surgery demonstrated significantly higher CB1 receptor expression in the L5 dorsal horn on postoperative days 4 and 7 (Figure 1). The changes in CB1 receptor expression were primarily apparent in 
the deeper laminae (III-V) of the dorsal horn in rats that had received L5NT surgery. CB1 receptor expression on day 1 after surgery was not significantly different between groups.
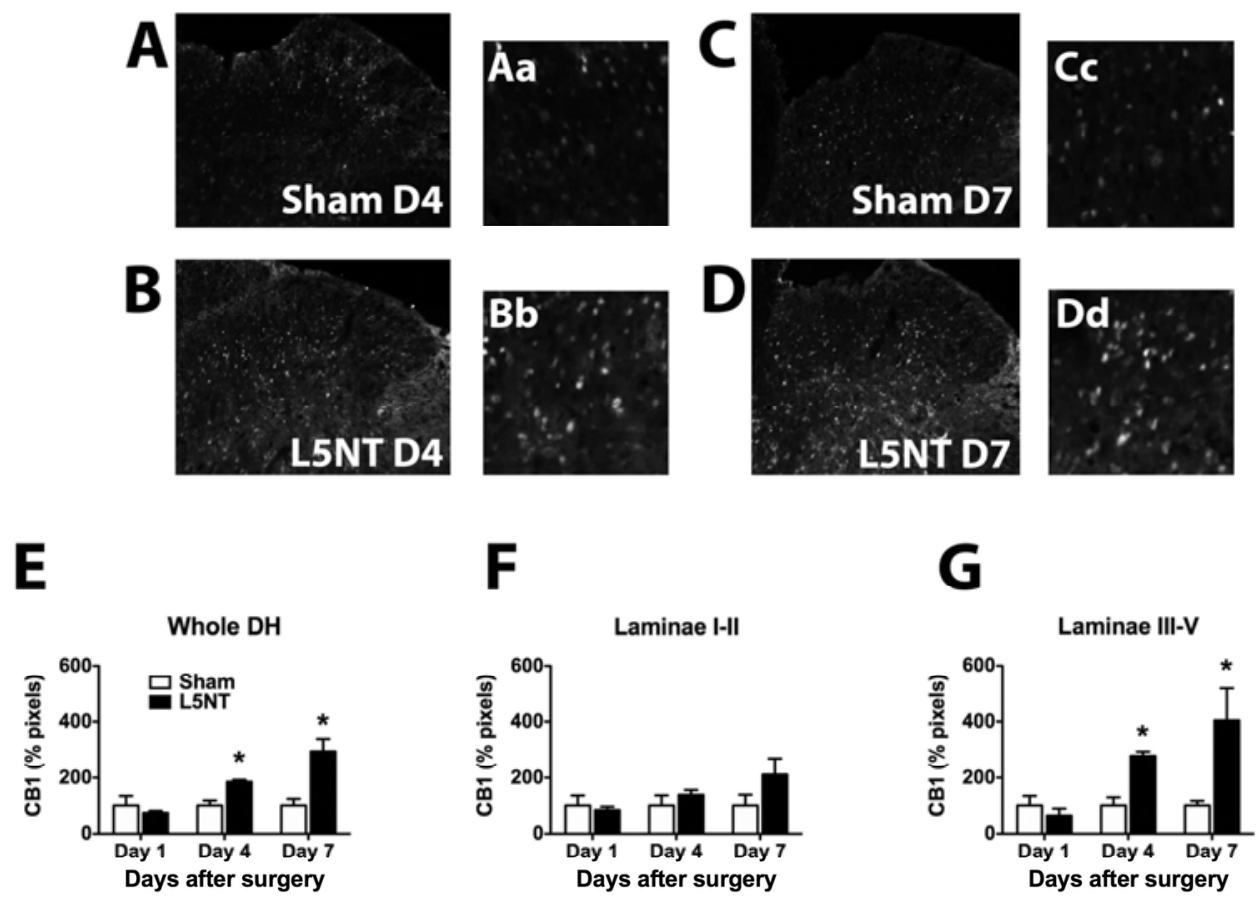

Fig. 1. CB1 receptor expression is increased on days 4 and 7 after L5 nerve transection. Representative images (A-D) show CB1 receptor expression at postoperative days 4 (D4) and 7 (D7) in the L5 dorsal horn of rats receiving sham surgery or L5 nerve transection. Details of the deep laminae (III-IV) of the dorsal horn of these spinal cord tissues are shown next to each original image (Aa-Dd). CB1 expression was quantified in the ipsilateral whole dorsal horn (E), laminae I-II (F) and laminae III-IV (G) of rats receiving sham surgery or L5 nerve transection at postoperative days 1,4 and 7 . Receptor expression was quantified as the number of pixels above a set threshold per total pixels in the selected area and normalized to percent of each control, sham group. ${ }^{*} \mathrm{p}<0.05 \mathrm{vs}$. respective sham group by $\mathrm{t}$ test. $\mathrm{N}=3 \mathrm{for}$ all groups.

Compared to the sham surgery group, rats receiving L5NT also demonstrated significantly higher spinal CB2 receptor expression on postoperative day 4 (Figure 2). This increased CB2 receptor expression was mainly observed in the superficial laminae (I-II) of the dorsal horn in animals with L5NT surgery. No significant changes in CB2 receptor expression were 
observed on postoperative days 1 or 7 following nerve injury compared to the sham surgery group.

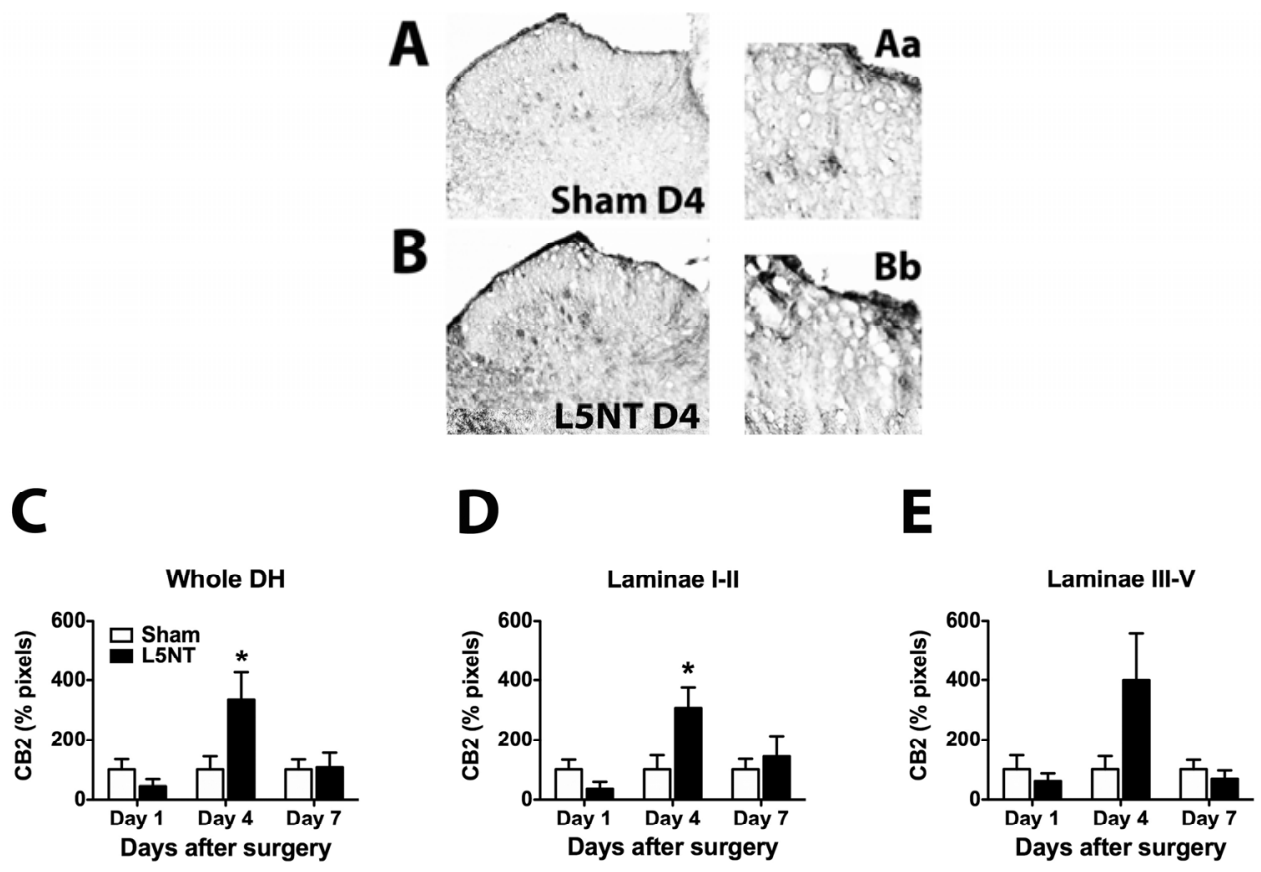

Fig. 2. CB2 receptor expression is increased on day 4 following L5 nerve transection. Representative images (A-B) show CB2 receptor expression at postoperative day 4 (D4) in the L5 dorsal horn of rats receiving sham surgery or L5 nerve transection. Details of the superficial laminae (II-III) of the dorsal horn of these spinal cord tissues are shown next to each original image (Aa and $\mathrm{Bb}$ ). CB2 expression was quantified in the ipsilateral whole dorsal horn (C), laminae I-II (D) and laminae III-IV (E) of rats receiving sham surgery or L5 nerve transection at postoperative days 1, 4 and 7 . Receptor expression was quantified as the number of pixels above a set threshold per total pixels in the selected area and normalized to percent of each control, sham group. ${ }^{*} \mathrm{p}<0.05$ vs. respective sham group by $\mathrm{t}$ test. $\mathrm{N}=3$ for all groups.

Using confocal microscopy, we observed that spinal CB1 receptors were primarily expressed on NeuN-positive neurons in the dorsal horns of animals receiving L5NT surgery (Figure 3). Occasionally, CB1 receptors expression co-localized with the astrocyte marker GFAP (Figure 3). CB1 receptor expression did not co-localize with Iba-1-positive microglia or ED2/CD163positive perivascular cells at any observed time point following L5NT (Figure 3). However, cells expressing CB1 receptor were in close proximity to Iba-1-positive microglia and perivascular cells. 

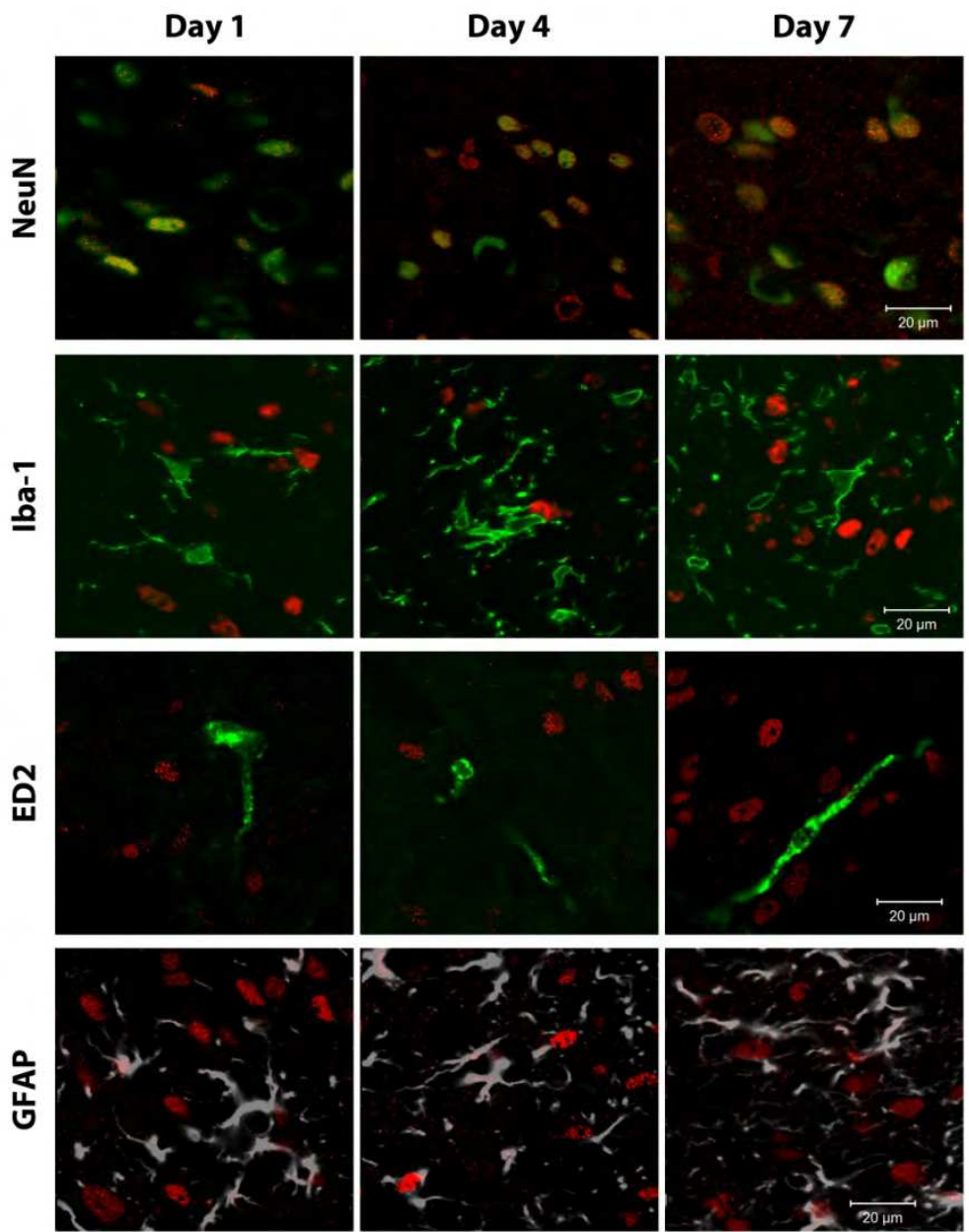

Fig. 3. CB1 receptor is expressed primarily in neurons. Representative confocal images show CB1 receptor cell localization in the ipsilateral L5 dorsal horn of rats at days 1, 4 and 7 after L5 nerve transection. CB1 receptor staining appears in red. NeuN (marker for neurons), Iba-1 (marker for microglia) and ED2/CD163 (ED2, marker for perivascular microglia) appear in green, and GFAP (marker for astrocytes) appears in grey. In the images of CB1 receptors and Iba-1, Iba-1 (originally in red) was changed to green, and CB1 receptor (originally in green) was changed to red to consistently show CB1 receptors in red in all images. GFAP color (originally in green) was changed to grey to obtain a better visualization of occasional expression of CB1 receptors on GFAP-positive cells. The colocalization of CB1 receptors with NeuN appears in yellow.

Microglia (Iba-1 positive cells) and perivascular cells (ED2/CD163 positive cells) displayed localized areas of CB2 receptor expression (Figure 4). Diffuse, punctate CB2 receptor 
expression was occasionally observed on NeuN-positive neuronal somata (Figure 4). Even though GFAP-positive spinal cord astrocytes did not demonstrate CB2 receptor expression, these cells were in close proximity to cells that expressed CB2 receptor (Figure 4).
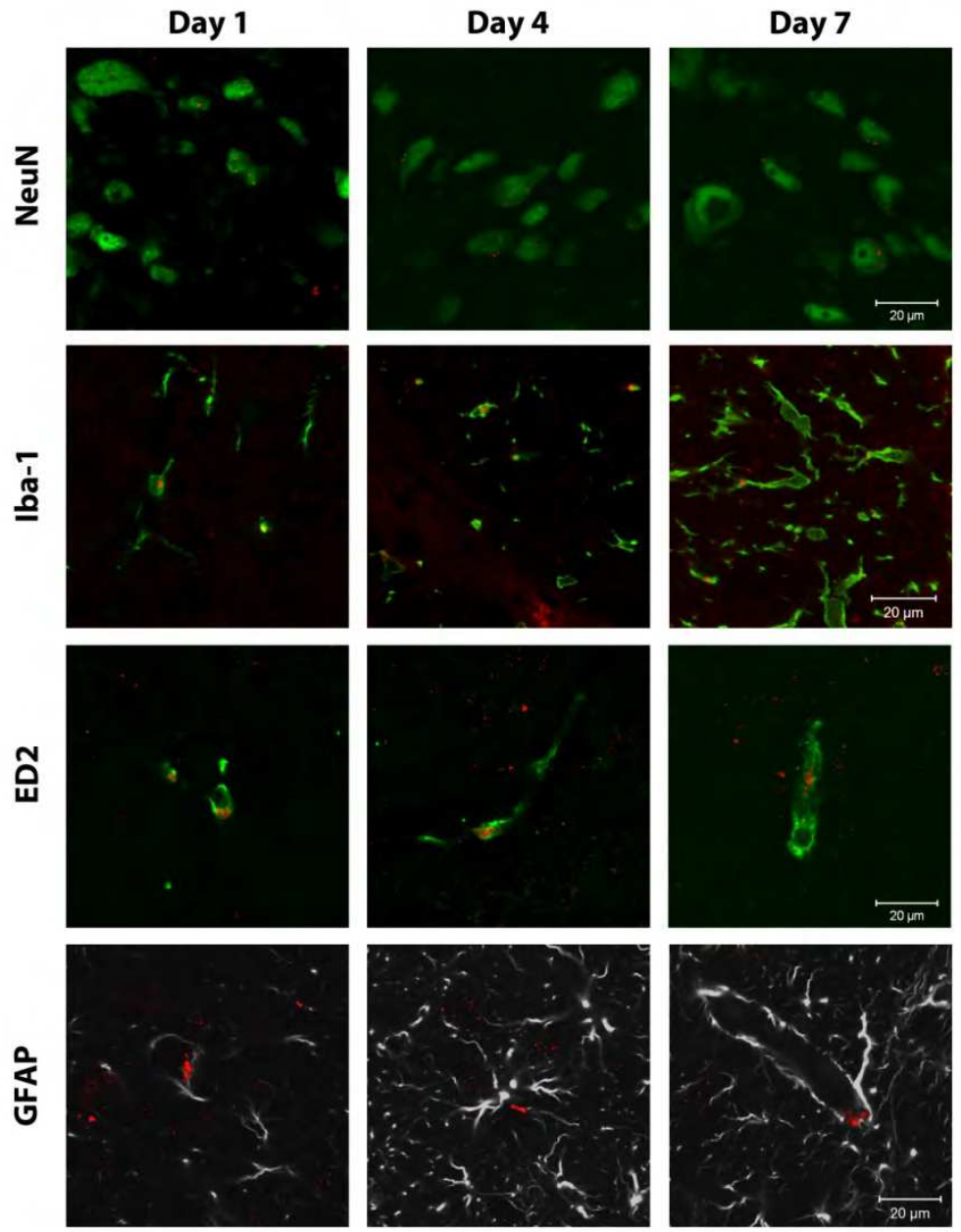

Fig. 4. CB2 receptors are mainly expressed in microglial cells. Representative confocal images show CB2 receptor cell localization in the ipsilateral L5 dorsal horn of rats at days 1, 4 and 7 after L5 nerve transection. CB2 receptor appears in red. NeuN (marker for neurons), Iba-1 (marker for microglia) and ED2/CD163 (ED2, marker for perivascular microglia) appear in green, and GFAP (marker for astrocytes) appears in grey. GFAP color (originally in green) was changed to grey to obtain a better visualization of this specific marker and any potential expression of $\mathrm{CB} 2$ receptors. The colocalization of $\mathrm{CB} 2$ receptors with the other cellular markers is visualized in yellow. 


\subsection{CP55940 antinociceptive tolerance}

Mechanical withdrawal thresholds on the uninjured side (paw contralateral to L5NT) were not affected by surgery $(26.7 \pm 1.4 \mathrm{~g}$ vs. $23.1 \pm 1.1 \mathrm{~g}$, before and after surgery respectively), nor were they significantly different at any observed time point during the five subsequent days of intrathecal vehicle or CP55940 administration (Figure 5). In the paw ipsilateral to L5NT surgery, withdrawal thresholds were significantly reduced after surgery $(26.6 \pm 1.3 \mathrm{~g}$ vs. $5.4 \pm 0.5 \mathrm{~g}$, before and after surgery respectively, $\mathrm{p}<0.05)$.
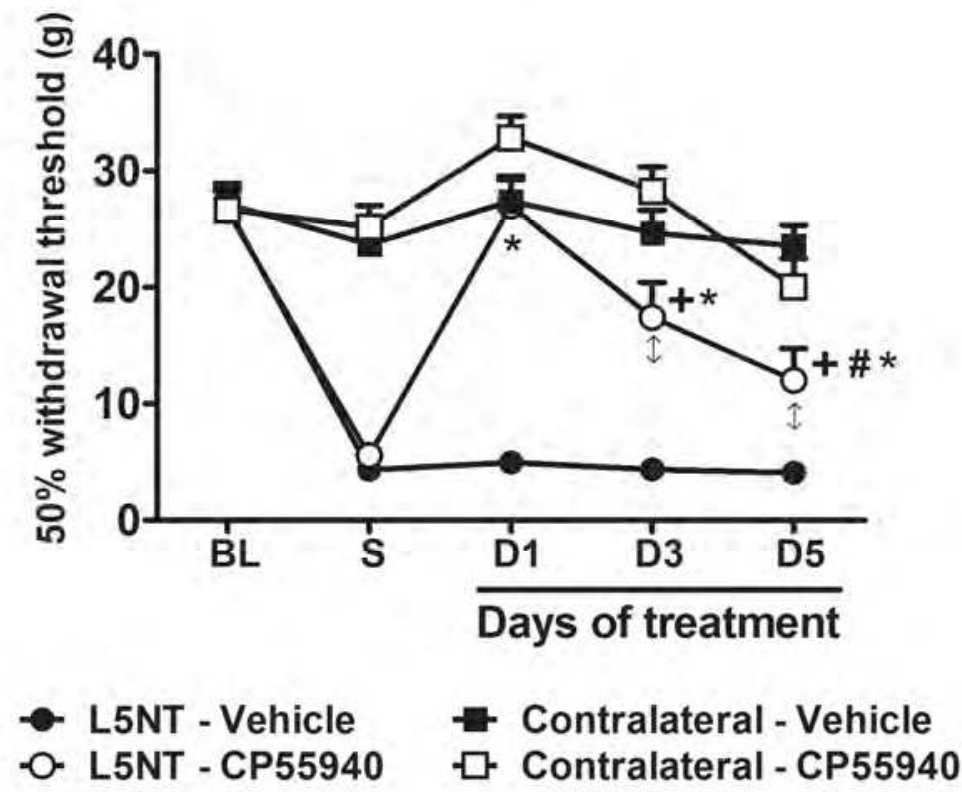

Fig. 5. Antinociceptive effects of repeated i.t. administration of CP55940. Paw withdrawal thresholds indicate responses to von Frey stimulation ipsilateral to L5NT or contralateral to surgery (uninjured side) before surgery (base line $=\mathrm{BL}$ ), four days after surgery (S), and $2 \mathrm{hr}$ after i.t. injections of vehicle $(n=17)$ or CP55940 $(n=18)$ on days 1, 3 and 5 . Withdrawal thresholds on day 1 (D1), day 3 (D3) and day 5 (D5) vs. after surgery data significantly differ by repeated measures one way ANOVA; * $\mathrm{p}<0.05$ vs. after surgery, $+\mathrm{p}<0.05$ vs.

D1 L5NT-CP55940, \# p<0.05 vs. D3 L5NT-CP55940 by repeated measures one way ANOVA followed by Tukey's multiple comparison test. Groups significantly differ by two way ANOVA; $1 \mathrm{p}<0.05$ compared to vehicle and both contralateral groups by two way ANOVA followed by Bonferroni post tests.

Administration of vehicle (i.t.) on each of the subsequent 5 days did not significantly alter this L5NT-induced hypersensitivity at any time point observed (Figure 5). In contrast, 
administration of the non-selective cannabinoid agonist CP55940 (100 $\mu$ g, i.t.) resulted in significantly higher withdrawal thresholds (measured 2 hours following injection) compared to vehicle-treated controls on each day observations were made (Figure 1). However, ipsilateral withdrawal thresholds in animals treated with CP55940 were significantly lower at $2 \mathrm{hr}$ after injection on days 3 - 5 compared to day 1 values (Figure 1 ). Additionally, the anti-allodynic effect of CP55940 was significantly lower at $2 \mathrm{hr}$ after injection on day 5 compared to day 3 (Figure 5).

In order to test the efficacy and potency of CP55940 before and after its repeated administration, we performed an acute dose escalation with i.t. CP55940. CP55940 reduced L5NT-induced hypersensitivity in a significant and dose-dependent manner before and 24 $\mathrm{hr}$ after the 5-day course of daily CP55940 administration (Figure 6). Compared to acute i.t. vehicle treatment, the minimum effective dose of CP55940 was $10 \mu \mathrm{g}$, and its maximum effective dose (dose that induced a return to base line values) was $50 \mu \mathrm{g}$ (the maximum dose tested) before and after its repeated administration. However, CP55940 displayed an approximately 2 -fold higher efficacy $(\mathrm{p}<0.05$, Table 2$)$ and an approximately 7 -fold higher potency $(\mathrm{p}<0.05$, Table 2$)$ in untreated animals (Figure 6A) than in animals previously treated with CP55940 for five days (repeated CP55940 group, Figure 6B). The higher efficacy and potency of CP55940 observed in untreated animals were similar to the ones observed in animals previously treated for five days with vehicle (repeated vehicle group, Figure 6C, Table 2). We then evaluated the effects of acute CP55940 two weeks after repeated treatment with CP55940 was discontinued (washout period). Even though acute CP55940 was still effective (at 10 and $50 \mu \mathrm{g}$ doses vs. vehicle) following 2 weeks of washout period, its efficacy and potency were significantly lower than in animals that had not received repeated CP55940 treatment (Figure 6D, Table 2). The acute antinociception induced by CP55940 50 $\mu \mathrm{g}$ (plus vehicle, $32.9 \pm 2.1 \mathrm{~g}, \mathrm{n}=6$ ) in the L5NT group was blocked by either the CB1 receptor antagonist AM281 $50 \mu \mathrm{g}(14.5 \pm 4.3 \mathrm{~g}, \mathrm{n}=4, \mathrm{P}<0.05)$ or the CB2 receptor antagonist AM630 50 $\mu \mathrm{g}(15.2 \pm 4.3 \mathrm{~g}, \mathrm{n}=4, \mathrm{P}<0.05)$, confirming that the activity of this compound depends on activation of both $\mathrm{CB} 1$ and $\mathrm{CB} 2$ receptors.

\begin{tabular}{|c|c|c|c|c|}
\cline { 2 - 5 } \multicolumn{1}{c|}{} & \multicolumn{2}{c|}{$\begin{array}{c}50 \% \text { w.t. for the } 50 \mu \mathrm{g} \text { dose } \\
\text { (efficacy in } \mathrm{g})\end{array}$} & \multicolumn{2}{c|}{$\begin{array}{c}\text { ED50 } \\
\text { (95\% confidence limits) }\end{array}$} \\
\cline { 2 - 5 } & CP55940 & JWH015 & CP55940 & JWH015 \\
\hline $\begin{array}{c}\text { L5NT no previous } \\
\text { treatment }\end{array}$ & $32.9 \pm 1.94$ & & $14.7(10.91-19.9)$ & \\
\hline $\begin{array}{c}24 \mathrm{hr} \text { after } \\
\text { repeated vehicle }\end{array}$ & $29.7 \pm 2.85$ & $17.0 \pm 2.7$ & $11.9(7.6-18.6)$ & $26.4(13.8-50.5)$ \\
\hline $\begin{array}{c}24 \text { hr after } \\
\text { repeated CP55940 }\end{array}$ & $14.9 \pm 1.12 *$ & $16.3 \pm 3.9$ & $112.6(21.2-596.6) *$ & $37.4(26.7-52.5)$ \\
\hline $\begin{array}{c}2 \text { weeks after } \\
\text { repeated CP55940 }\end{array}$ & $15.7 \pm 4.8 *$ & $14.2 \pm 2.5$ & $162.6(5.7-4567) *$ & $32.5(1.2-872)$ \\
\hline
\end{tabular}

Table 2. Effect of the highest dose $(50 \mu \mathrm{g})$ and ED50 (95\% confidence limits) of acute i.t. administration of CP55940 and JWH015 in L5NT, * $\mathrm{P}<0.05$ vs. L5NT no previous treatment and $24 \mathrm{hr}$ after repeated vehicle groups. Withdrawal threshold $=$ w.t. 


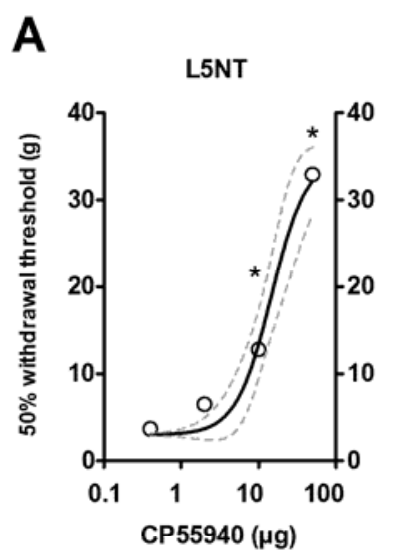

\section{Acute CP}

B

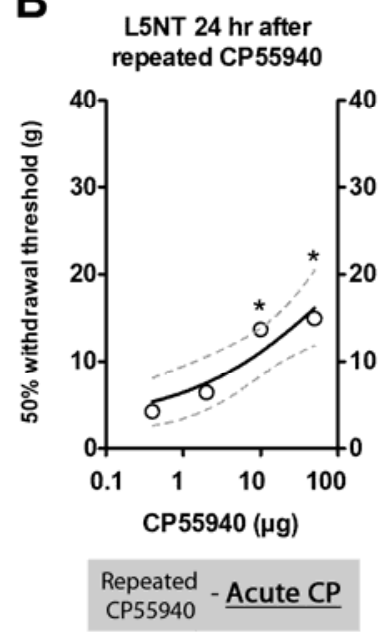

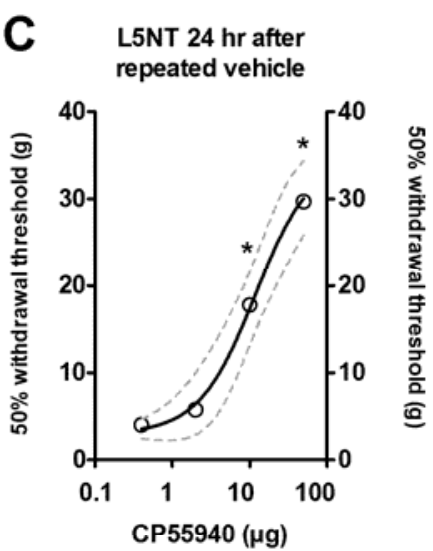
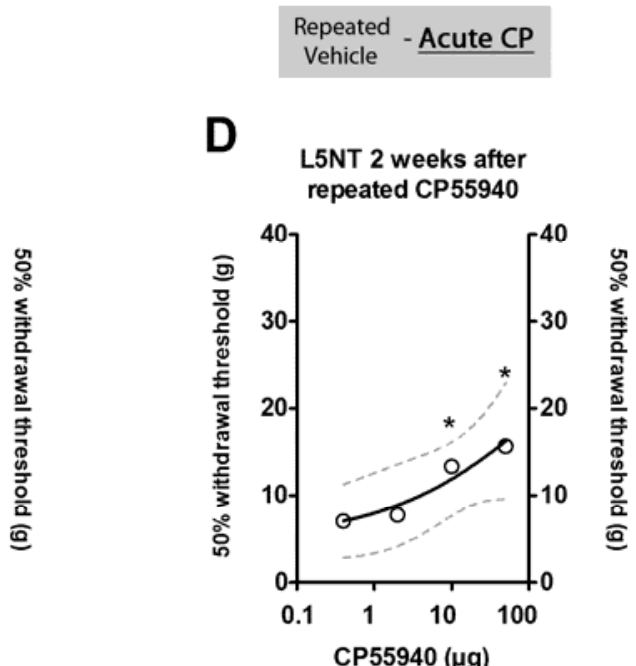

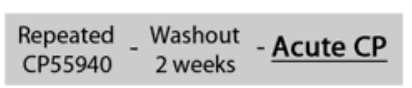

Fig. 6. Antinociceptive effects of acute i.t. administration of CP55940. Withdrawal thresholds (95\% confidence limits, doted lines) indicate responses to von Frey stimulation ipsilateral to L5NT surgery 15 min after escalating doses $(0.4,2,10$ and $50 \mu$ g) of i.t. CP55940 in animals receiving no additional treatment $(A, n=5), 24 \mathrm{hr}$ after the discontinuation of repeated treatment (5 days) with CP55940 i.t., $100 \mu \mathrm{g}(\mathrm{B}, \mathrm{n}=6)$ or vehicle $(\mathrm{C}, \mathrm{n}=6)$ and 2 weeks (washout period) after the discontinuation of repeated treatment (5 days) with CP55940 $100 \mu \mathrm{g}(\mathrm{D}, \mathrm{n}=5)$. Withdrawal thresholds in response to dose escalation of CP55940 significantly differ from after-surgery values by repeated measures one way ANOVA, ${ }^{*} \mathrm{p}<0.05$ vs. after surgery by repeated measures one way ANOVA followed by Tukey's multiple comparison test. Groups significantly differ by two way ANOVA; $<<0.05$ L5NT or L5NT $24 \mathrm{hr}$ after repeated vehicle groups vs. L5NT $24 \mathrm{hr}$ after repeated CP55940 or L5NT 2 weeks after repeated CP55940 groups for $50 \mu \mathrm{g}$ by two way ANOVA followed by Bonferroni post tests. 


\subsection{CP55940 neurological side effects}

In order to investigate the neurological side effects of CP55940 administration, we evaluated the place-stepping reflex, vocalization, exploratory activity and the bar test. Repeated vehicle injection did not significantly affect any of these behaviors at any time point observed. CP55940 significantly impaired the placing-stepping reflex (Figure 7A), induced vocalization (Figure 7B) and reduced exploratory activity (Figure 7C) on days 1, 2 and 3 compared to vehicle group, and induced catalepsy (Figure 7D) on days 1, 2, 3 and 4
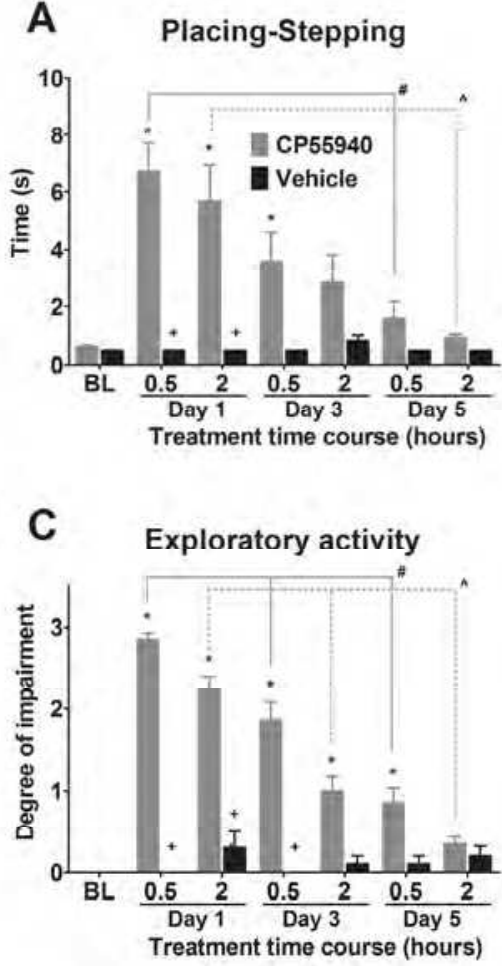
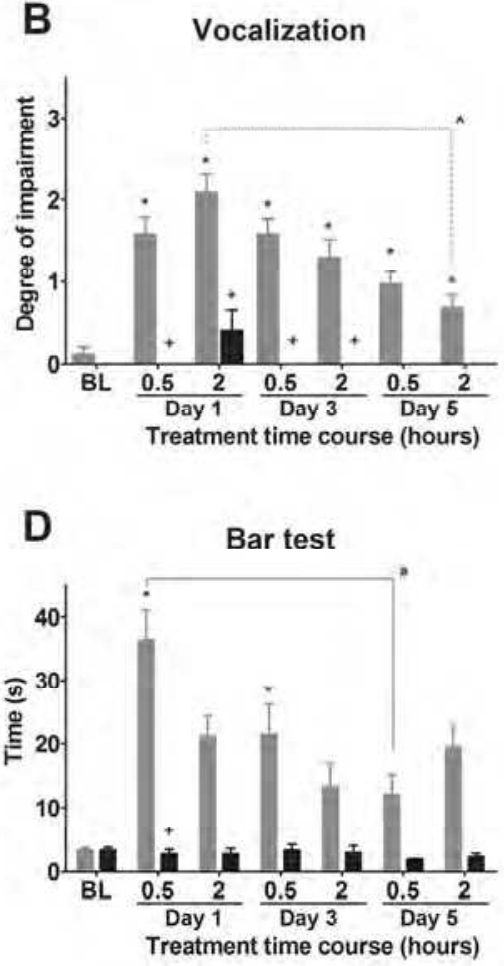

Fig. 7. Neurological side effects in response to repeated treatment with CP55940. Placingstepping (A), vocalization (B), exploratory activity (C) and bar test (C) scores are shown from before the first injection (base line $=\mathrm{BL}$ ), and $0.5,2$ and $24 \mathrm{hr}$ after each i.t. injection (days 1 - 5) of vehicle $(n=8)$ or CP55940 (n=13) during five consecutive days. Withdrawal thresholds on days 1,3 and 5 in placing-stepping and bar test vs. base line data significantly differ by repeated measures one way ANOVA, * $p<0.05$ vs. base line, \#p $<0.05$ vs. $0.5 \mathrm{hr}$, $\wedge \mathrm{p}<0.05 \mathrm{vs} .2 \mathrm{hr}$ by repeated measures one way ANOVA followed by Tukey's multiple comparison test. Groups differ in placing-stepping and bar test by repetitive measurements two-way ANOVA, + p< 0.05 vs. CP55940 group by two way ANOVA followed by Bonferroni post tests. Days 1, 3 and 5 values in vocalization and exploratory activity vs. base line significantly differ by Friedman test, ${ }^{*} \mathrm{p}<0.05$ vs. base line, $\# \mathrm{p}<0.05$ vs. $0.5 \mathrm{hr},{ }^{\wedge} \mathrm{p}<0.05$ vs. $2 \mathrm{hr}$ by Friedman test followed by Wilcoxon test. Groups in vocalization and exploratory activity significantly differ by Kruskal-Wallis test; $+p<0.05$ vs. CP55940 by Kruskal-Wallis test followed by Mann-Whitney U test. 
compared to vehicle group. The magnitude of these neurological side effects decreased over the 5-day course of daily CP55940 injections until they were not significantly different compared to vehicle group on days 4 and 5 (except for catalepsy, $2 \mathrm{hr}$ after CP55940 injection on day 4 vs. vehicle group, $\mathrm{p}<0.05)$. The righting reflex was significantly impaired by CP55940 compared to base line on days 1 and 3 (30 min and $2 \mathrm{hr}$ after injections, data not shown). The effects of CP55940 on placing-stepping reflex, vocalization and bar test on day 1 were significantly higher compared to its effects on days 4 and 5. The effects of CP55940 on exploratory activity on day 1 were significantly higher compared to its effects on days 3,4 and 5. For clarity, only the data obtained on days 1,3 and 5 of treatment are shown.

\subsection{Acute antinociceptive effect of JWH015 in CP55940-tolerant animals}

JWH015, a selective CB2 receptor agonist, reduced mechanical hypersensitivity ipsilateral to surgery in a dose-dependent fashion when administered i.t. in cumulative, escalating doses in animals previously exposed to CP55940 or vehicle (Figure 8A). The minimum and

A

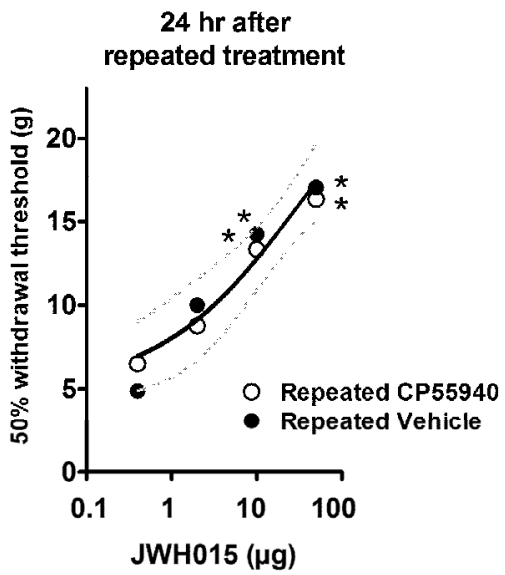

Repeated - Acute JWH
CP or Veh
B

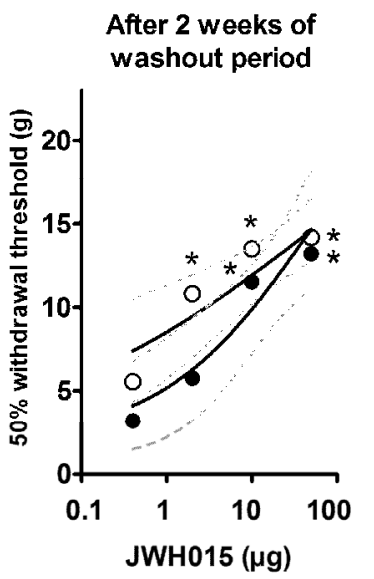

Repeated - Washout - Acute JWH

Fig. 8. Antinociceptive effects of acute i.t. administration of JWH015 in CP55940-mediated tolerant animals. Withdrawal thresholds (95\% confidence limits, doted lines) indicate responses to von Frey stimulation ipsilateral to L5NT surgery 15 min after escalating doses $(0.4,2,10$ and $50 \mu \mathrm{g})$ of i.t. JWH015 administered $24 \mathrm{hr}(\mathrm{A})$ or two weeks (washout period, B) after the discontinuation of repeated treatment with CP55940 $100 \mu \mathrm{g}$ (Repeated CP55940) or vehicle (Repeated Vehicle). Groups did not differ by two-way ANOVA. Withdrawal thresholds after each dose vs. after surgery values significantly differ by repeated measures one way ANOVA, * $\mathrm{p}<0.05$ vs. after surgery by repeated measures one way ANOVA followed by Tukey's multiple comparison test. Twenty-four hr after repeated treatment cessation: Repeated CP55940 n=8, Repeated Vehicle n=8, Repeated CP55940-washout period $\mathrm{n}=6$ and Repeated Vehicle-washout period $\mathrm{n}=5$. 
maximum effective doses of JWH015 in the repeated CP55940 group were 10 and $50 \mu \mathrm{g}$ respectively (50 $\mu \mathrm{g}$ was the highest dose used). JWH015 was equally effective in both repeated CP55940 and vehicle groups since no significant difference in withdrawal thresholds was observed between groups in any dose tested. As a result, the ED50 value [95\% confidence limits] of JWH015 was not significantly different in animals previously treated with repeated CP55940 compared to animals previously treated with vehicle (Table 1 and Figure 8A). Vehicle (same paradigm as cumulative JWH015) did not modify the withdrawal thresholds ipsilateral to surgery ( $3.5 \pm 0.6$ vs. $5.3 \pm 1.4 \mathrm{~g}$ before and 15 min after the last injection respectively, $\mathrm{n}=6) 24 \mathrm{hr}$ after repeated treatment with vehicle.

JWH015 was also effective in reversing the L5NT-induced hypersensitivity when it was administered in a cumulative manner two weeks after the cessation of CP5940 treatment (washout period). In this case, the minimum and maximum effective dose of JWH015 were 2 and $50 \mu \mathrm{g}$ respectively in animals previously exposed to CP55940 (repeated CP55940 group), and 10 and $50 \mu \mathrm{g}$ respectively in animals previously treated with vehicle (repeated vehicle group). Similar efficacy and potency of JWH015 were observed in both repeated CP55940 and vehicle groups (Table 2). No significant difference in withdrawal thresholds was observed between groups in any dose tested (Figure 8B). Vehicle (same paradigm as cumulative JWH015) did not modify the withdrawal thresholds ipsilateral to surgery in the repeated vehicle group after the two-week washout period ( $3.5 \pm 0.6 \mathrm{vs}$. $3.6 \pm 0.7 \mathrm{~g}$ before and $15 \mathrm{~min}$ after the last injection respectively, $\mathrm{n}=6$ ). The acute antinociception induced by JWH015 $50 \mu \mathrm{g}$ (plus vehicle, $17 \pm 2.7 \mathrm{~g}$, n=8) in the L5NT group was completely blocked by the $\mathrm{CB} 2$ receptor antagonist AM630 $50 \mu \mathrm{g}(2.4 \pm 0.4 \mathrm{~g}, \mathrm{n}=4, \mathrm{P}<0.05)$.

\subsection{Antinociceptive effect of a CB2 receptor agonist administered repeatedly in CP55940 tolerant animals studies}

JWH015 injected i.t. for four consecutive days induced similar antinociceptive effects on all days tested in animals previously exposed to repeated i.t. vehicle treatment (for 5 days) and a washout period of two weeks. However, JWH015 injected i.t. for four consecutive days induced antinociception only on days 1 and 4 in animals previously exposed to sustained spinal CP55940 administration (for 5 days) and a washout period of two weeks. Repeated i.t. JWH015 was significantly less effective on the last three days of treatment in animals previously exposed to repeated CP55940 when compared to those previously exposed to repeated vehicle (Figure 9A). The JWH015 repeated treatment did not modify the mechanical withdrawal threshold in the contralateral paw in the repeated vehicle or CP55940 group, and the effects of repeated JWH015 did not differ between groups, except on day 3 when the withdrawal threshold was significantly higher in the repeated vehicle group than the CP55940 one (Figure 9B). Vehicle (same paradigm as repeated JWH015) did not modify the withdrawal thresholds ipsilateral $(n=6)$ or contralateral $(n=6)$ to surgery in the repeated CP55940 group after the two-week washout period (data not shown).

\section{Discussion}

The main findings of our study are: 1) the repeated administration of a non-selective cannabinoid agonist (CP55940) induces antinociceptive tolerance and tolerance to cannabinoid-induced neurological side effects in a rat model of neuropathic pain; 2) CP55940 tolerance persists two weeks after the discontinuation of cannabinoid administration; 3) prior induction of CP55940 tolerance reduced the antinociceptive effect of 
repeated administration of a CB2 receptor agonist (JWH015), but did not alter the antinociceptive response to acute JWH015 dose escalation.

A

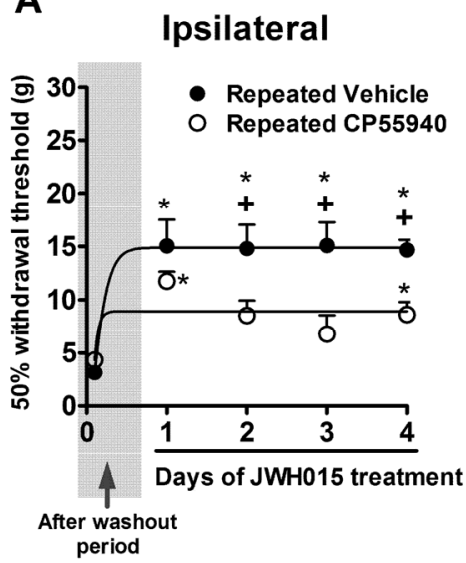

B

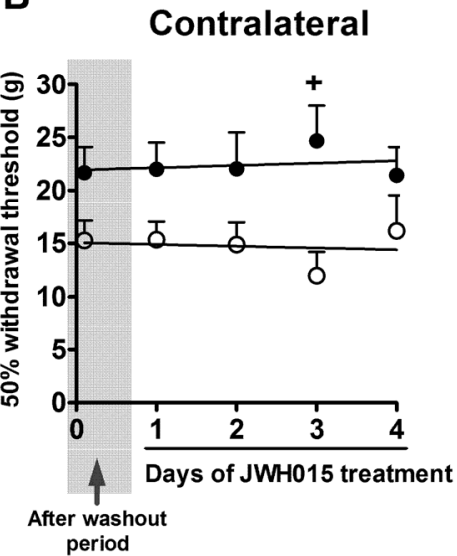

Fig. 9. Antinociceptive effects of repeated i.t. administration of JWH015 in CP55940mediated tolerant animals. Paw withdrawal thresholds indicate responses to von Frey stimulation ipsilateral to L5NT (A) or contralateral to surgery (uninjured side, B) two weeks after the cessation of repeated CP55940 or vehicle administration (After washout period), and $2 \mathrm{hr}$ after each i.t. injection of JWH015 during four consecutive days. Withdrawal thresholds on days 1-4 vs. after washout period data significantly differ by repeated measures one way ANOVA, * $\mathrm{p}<0.05$ after washout period by repeated measures one way ANOVA followed by Tukey's multiple comparison test. Groups significantly differ by two way ANOVA; + p <0.05 compared to vehicle group by two way ANOVA followed by Bonferroni post tests.

We demonstrate that a non-selective cannabinoid agonist administered repeatedly at a concentration that induces neurological side effects (such as the effects that regular cannabis users seek for recreational purposes) is sufficient to produce a long lasting antinociceptive tolerance that persists weeks after the cessation of drug exposure. In agreement with these findings, diminished psychotropic effects (D'Souza et al., 2008) and analgesic tolerance to delta-9-tetrahydrocannabinol (Clark et al., 1981) have been demonstrated in frequent users of cannabis. This hypothesis has been further supported by a double-blind, placebocontrolled study demonstrating evidence of dronabinol tolerance in regular marijuana users (Bedi et al., 2010). It has also been shown that repeated administration of CB1 receptor agonists results in antinociceptive tolerance in naïve mice and rats (Gardell et al., 2002; Hama and Sagen, 2009), and that this tolerance is dependent on spinal cord mechanisms (Gardell et al., 2002). In contrast, we have previously shown that i.t. administration of the CB2 receptor agonist JWH015 effectively reverses L5 nerve transection-induced behavioral hypersensitivity without antinociceptive tolerance through at least five days of treatment (Romero-Sandoval and Eisenach, 2007). Similar findings have been described with another CB2 receptor agonist, A-836339 (Yao et al., 2009). Taken together, these previous findings suggest that $\mathrm{CB} 1$ rather than $\mathrm{CB} 2$ receptor agonism is responsible for the antinociceptive 
tolerance observed in response to CP55940 administration in the current study. Repeated administration of CP55940 also induced tolerance to a range of neurological side effects. We have previously observed that CP55940-induced neurological side effects are dependent on CB1 receptor activation, but not on $\mathrm{CB} 2$ receptor activation in rat postoperative and neuropathic pain models (Romero-Sandoval and Eisenach, 2007; Romero-Sandoval et al., 2008a). While these findings support the potential role of CB1 receptors in cannabinoid induced tolerance in our neuropathic pain model, CB1 receptor agonism does not induce antinociceptive tolerance in a spinal cord injury model (Hama and Sagen, 2009). Therefore, agonism of both CB1 and CB2 receptors may be required to induce antinociceptive tolerance to cannabinoid therapies in animals or patients with peripheral or central nerve injury.

CB1 receptor-dependent cross-tolerance among cannabinoids has recently been described between delta-tetrahydrocannabinol (the active ingredient of cannabis) and anandamide (one of the major endocannabinoids) (Falenski et al., 2010), and between 2arachidonylglycerol (another major endocannabinoid) and the CB1 receptor agonist WIN55,212-2 (Schlosburg et al., 2010). This cross-tolerance is thought to be CB1-dependent (Falenski et al., 2010). However, we demonstrate in our current study that repeated administration of JWH015 exhibited reduced efficacy in rats with peripheral nerve injury that have been previously exposed to a non-selective cannabinoid agonist. This finding directly contrasts with our previous observation that repeated JWH015 reduces L5NTinduced hypersensitivity without signs of tolerance in the same rat model of neuropathic pain (Romero-Sandoval et al., 2008a). Taken together, these findings indicate that cannabinoid antinociceptive tolerance to non-selective cannabinoid agonists affects subsequent responsiveness of both CB1 and CB2 receptors. We also observed that CB1 receptors are predominantly expressed in neurons and that $\mathrm{CB} 2$ receptors are predominantly expressed in microglia in the spinal cord of both sham surgery and L5NT groups. Therefore, neuronal and glial interactions may contribute to the effects of CP55940induced tolerance on JWH015's antinociceptive effectiveness.

Cannabinoid tolerance depends on CB receptor availability (Tappe-Theodor et al., 2007; Martini et al., 2010) and/or sensitivity (Jin et al., 1999; Selley et al., 2004). These receptor properties may change following peripheral insults such as paw incision (Alkaitis et al., 2010), peripheral nerve injury (Lim et al., 2003) or sustained activation by endogenous (Falenski et al., 2010; Schlosburg et al., 2010) or exogenous cannabinoids (Gardell et al., 2002; Hama and Sagen, 2009). In accordance with our findings, others have shown that a single intracerebroventricular dose of CB1 receptor agonists (WIN55,212-2 or ACEA) induces antinociceptive tolerance that lasts for more than 14 days through actions on the pertussis toxin-insensitive G proteins, Gz (Garzon et al., 2009). The mechanisms involved in long lasting CB1 receptor-mediated tolerance may also include the persistent cellular internalization or degradation of CB1 receptor (Sim-Selley et al., 2006). These data suggest that cannabinoid responsiveness and tolerance are shaped by a number of factors including type of pain or injury, exposure to endogenous or exogenous cannabinoids and receptor expression and sensitivity.

\section{Conclusion}

We demonstrate that a non-selective cannabinoid drug induces tolerance under neuropathic pain conditions, that this tolerance persists several weeks after the suspension of the treatment and that this tolerance affects the antinociceptive effects of repeated 
administration of a CB2 receptor agonist. These findings suggest that potential future analgesic drugs based on selective actions on CB2 receptor may not be a good alternative for long-term treatment in patients previously exposed to chronic cannabinoids. These results build on previous published data demonstrating that central CB1 receptor-mediated tolerance enhances tolerance to opioids (Trang et al., 2007; Garzon et al., 2009) and nonsteroidal anti-inflammatory agents (Anikwue et al., 2002). Further research is needed to determine the mechanisms for this broad cross-tolerance among distinct drug classes. Additional studies are also warranted to determine whether patients with histories of cannabis or cannabinoid-based drug use for recreational or medical purposes demonstrate tolerance to common analgesic therapies.

\section{Acknowledgements}

Supported in part by grants DA025211 (AR-S) and DA11276 (JAD) from the National Institutes of Health (Bethesda, MD), and the American Pain Society Future Leaders in Pain Research grant. The authors declare that there are no conflicts of interest.

\section{References}

Alkaitis, MS., Solorzano, C., Landry, RP., Piomelli, D., DeLeo, JA., \& Romero-Sandoval, EA. (2010). Evidence for a role of endocannabinoids, astrocytes and p38 phosphorylation in the resolution of postoperative pain. PLoS One, Vol. 5:e10891

Anikwue, R., Huffman, JW., Martin, ZL., \& Welch, SP. (2002). Decrease in efficacy and potency of nonsteroidal anti-inflammatory drugs by chronic delta(9)tetrahydrocannabinol administration. J Pharmacol Exp Ther, Vol. 303, No. 1, pp. 34046

Bedi, G., Foltin, RW., Gunderson, EW., Rabkin, J., Hart, CL., Comer, SD., Vosburg, SK., \& Haney, M. (2010). Efficacy and tolerability of high-dose dronabinol maintenance in HIV-positive marijuana smokers: a controlled laboratory study. Psychopharmacology (Berl), Vol. 212, No. 4, pp. 675-86

Chaplan, SR., Bach, FW., Pogrel, JW., Chung, JM., \& Yaksh, TL. (1994). Quantitative assessment of tactile allodynia in the rat paw. J Neurosci Methods, Vol. 43, No. 1, pp. $55-63$

Clark, WC., Janal, MN., Zeidenberg, P., \& Nahas, GG. (1981). Effects of moderate and high doses of marihuana on thermal pain: a sensory decision theory analysis. J Clin Pharmacol, Vol 21, pp. 299S-310S

D'Souza, DC., Ranganathan, M., Braley, G., Gueorguieva, R., Zimolo, Z., Cooper, T., Perry, E., \& Krystal, J. (2008). Blunted Psychotomimetic and Amnestic Effects of Delta-9Tetrahydrocannabinol in Frequent Users of Cannabis. Neuropsychopharmacology, Vol 33, No. 10, pp. 2505-16

Falenski, KW., Thorpe, AJ., Schlosburg, JE., Cravatt, BF., Abdullah, RA., Smith, TH., Selley, DE., Lichtman, AH., \& Sim-Selley, LJ. (2010). FAAH-/- mice display differential tolerance, dependence, and cannabinoid receptor adaptation after delta 9tetrahydrocannabinol and anandamide administration. Neuropsychopharmacology, Vol 35, No. 8, pp. 1775-1787 
Gardell, LR., Burgess, SE., Dogrul, A., Ossipov, MH., Malan, TP., Lai, J., \& Porreca, F. (2002). Pronociceptive effects of spinal dynorphin promote cannabinoid-induced pain and antinociceptive tolerance. Pain, Vol. 98, pp. 79-88

Garzon, J., de la Torre-Madrid, E., Rodriguez-Munoz, M., Vicente-Sanchez, A., \& SanchezBlazquez, P. (2009). Gz mediates the long-lasting desensitization of brain CB1 receptors and is essential for cross-tolerance with morphine. Mol Pain, Vol. 5, No. 11

Hama, A., \& Sagen, J. (2009). Sustained antinociceptive effect of cannabinoid receptor agonist WIN 55,212-2 over time in rat model of neuropathic spinal cord injury pain. J Rehabil Res Dev, Vol. 46, No. 1, pp. 135-143

Jin, W., Brown, S., Roche, JP., Hsieh, C., Celver, JP., Kovoor, A., Chavkin, C., \& Mackie, K. (1999). Distinct domains of the CB1 cannabinoid receptor mediate desensitization and internalization. J Neurosci, Vol. 19, No. 10, pp. 3773-3780

Lim, G., Sung, B., Ji, RR., \& Mao, J. (2003). Upregulation of spinal cannabinoid-1-receptors following nerve injury enhances the effects of Win 55,212-2 on neuropathic pain behaviors in rats. Pain, Vol. 105, pp. 275-283

Martini, L., Thompson, D., Kharazia, V., \& Whistler, JL. (2010). Differential regulation of behavioral tolerance to WIN55,212-2 by GASP1. Neuropsychopharmacology, Vol. 35, No. 6, pp. 1363-1373

Romero-Sandoval, A., \& Eisenach, JC. (2007). Spinal cannabinoid receptor type 2 activation reduces hypersensitivity and spinal cord glial activation after paw incision. Anesthesiology, Vol. 106, No. 4, pp. 787-794

Romero-Sandoval, A., Nutile-McMenemy, N., \& DeLeo, JA. (2008a). Spinal microglial and perivascular cell cannabinoid receptor type 2 activation reduces behavioral hypersensitivity without tolerance after peripheral nerve injury. Anesthesiology, Vol. 108, No. 4, pp. $722-734$

Romero-Sandoval, A., Chai, N., Nutile-McMenemy, N., \& DeLeo, JA. (2008b). A comparison of spinal Iba1 and GFAP expression in rodent models of acute and chronic pain. Brain Research, Vol. 1219, pp. 116-26

Schlosburg, JE., Blankman, JL., Long, JZ., Nomura, DK., Pan, B., Kinsey, SG., Nguyen, PT., Ramesh, D., Booker, L., Burston, JJ., Thomas, EA., Selley, DE., Sim-Selley, LJ., Liu, QS., Lichtman, AH., \& Cravatt, BF. (2010). Chronic monoacylglycerol lipase blockade causes functional antagonism of the endocannabinoid system. Nat Neurosci, Vol. 13, No. 9, pp. 1113-1119

Selley, DE., Cassidy, MP., Martin, BR., \& Sim-Selley, LJ. (2004). Long-term administration of Delta9-tetrahydrocannabinol desensitizes CB1-, adenosine A1-, and GABABmediated inhibition of adenylyl cyclase in mouse cerebellum. Mol Pharmacol, Vol. 66, No. 5, pp. 1275-1284

Sim-Selley, LJ., Schechter, NS., Rorrer, WK., Dalton, GD., Hernandez, J., Martin, BR., \& Selley, DE. (2006). Prolonged recovery rate of CB1 receptor adaptation after cessation of long-term cannabinoid administration. Mol Pharmacol, Vol. 70, No. 3, pp. $986-996$

Tanga, FY., Nutile-McMenemy, N., \& DeLeo, JA. (2005). The CNS role of Toll-like receptor 4 in innate neuroimmunity and painful neuropathy. Proc Natl Acad Sci U S A, Vol. 102, No. 16, pp. 5856-5861 
Tappe-Theodor, A., Agarwal, N., Katona, I., Rubino, T., Martini, L., Swiercz, J., Mackie, K., Monyer, H., Parolaro, D., Whistler, J., Kuner, T., \& Kuner, R. (2007). A molecular basis of analgesic tolerance to cannabinoids. J Neurosci, Vol. 27, No. 15, pp. 41654177

Trang, T., Sutak, M., \& Jhamandas, K. (2007). Involvement of cannabinoid (CB1)-receptors in the development and maintenance of opioid tolerance. Neuroscience, Vol. 146, No. 3 , pp. $1275-1288$

Wade, DT., Makela, P., Robson, P., House, H., \& Bateman, C. (2004). Do cannabis-based medicinal extracts have general or specific effects on symptoms in multiple sclerosis? A double-blind, randomized, placebo-controlled study on 160 patients. Mult Scler, Vol. 10, No. 4, pp. 434-441

Yao, BB., Hsieh, G., Daza, AV., Fan, Y., Grayson, GK., Garrison, TR., El Kouhen, O., Hooker, BA., Pai, M., Wensink, EJ., Salyers, AK., Chandran, P., Zhu, CZ., Zhong, C., Ryther, K., Gallagher, ME., Chin, CL., Tovcimak, AE., Hradil, VP., Fox, GB., Dart, MJ., Honore, P., \& Meyer MD. (2009). Characterization of a cannabinoid CB2 receptorselective agonist, A-836339 [2,2,3,3-tetramethyl-cyclopropanecarboxylic acid [3-(2methoxy-ethyl)-4,5-dimethyl-3H-thiazol-(2Z)-ylidene]-amide], using in vitro pharmacological assays, in vivo pain models, and pharmacological magnetic resonance imaging. J Pharmacol Exp Ther, Vol. 328, No. 1, pp. 141-151 


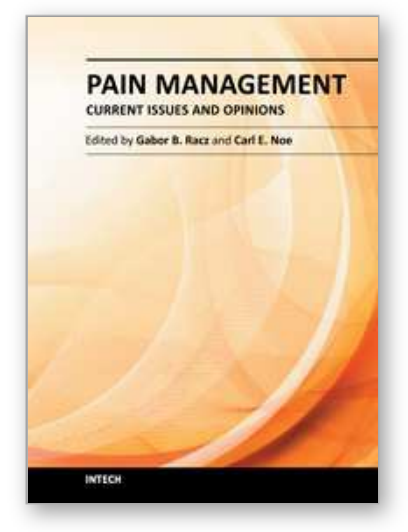

\author{
Pain Management - Current Issues and Opinions \\ Edited by Dr. Gabor Racz
}

ISBN 978-953-307-813-7

Hard cover, 554 pages

Publisher InTech

Published online 18, January, 2012

Published in print edition January, 2012

Pain Management - Current Issues and Opinions is written by international experts who cover a number of topics about current pain management problems, and gives the reader a glimpse into the future of pain treatment. Several chapters report original research, while others summarize clinical information with specific treatment options. The international mix of authors reflects the "casting of a broad net" to recruit authors on the cutting edge of their area of interest. Pain Management - Current Issues and Opinions is a must read for the up-to-date pain clinician.

\title{
How to reference
}

In order to correctly reference this scholarly work, feel free to copy and paste the following:

Matthew S. Alkaitis, Christian Ndong, Russell P. Landry III, Joyce A. DeLeo and E. Alfonso Romero-Sandoval (2012). Reduced Antinociceptive Effect of Repeated Treatment with a Cannabinoid Receptor Type 2 Agonist in Cannabinoid-Tolerant Rats Following Spinal Nerve Transection, Pain Management - Current Issues and Opinions, Dr. Gabor Racz (Ed.), ISBN: 978-953-307-813-7, InTech, Available from:

http://www.intechopen.com/books/pain-management-current-issues-and-opinions/reduced-antinociceptiveeffect-of-repeated-treatment-with-a-cannabinoid-receptor-type-2-agonist-in-c

\section{INTECH}

open science | open minds

\section{InTech Europe}

University Campus STeP Ri

Slavka Krautzeka 83/A

51000 Rijeka, Croatia

Phone: +385 (51) 770447

Fax: +385 (51) 686166

www.intechopen.com

\section{InTech China}

Unit 405, Office Block, Hotel Equatorial Shanghai

No.65, Yan An Road (West), Shanghai, 200040, China

中国上海市延安西路65号上海国际贵都大饭店办公楼405单元

Phone: +86-21-62489820

Fax: +86-21-62489821 
(C) 2012 The Author(s). Licensee IntechOpen. This is an open access article distributed under the terms of the Creative Commons Attribution 3.0 License, which permits unrestricted use, distribution, and reproduction in any medium, provided the original work is properly cited. 